\title{
Metabolic regulation during sport events: factual interpretations and inadequate allegations
}

CDD. 20.ed. 612.39

796.027
Jacques Remy POORTMANS* Alain CARPENTIER*
*Faculty of Motor Sciences, Free University of Brussels Belgium.

\begin{abstract}
Different fuels are available to generate ATP for muscle activities during sport events. Glycogen from striated muscles and liver stores may be converted to lactic acid or almost completely oxidized to carbon dioxide $\left(\mathrm{CO}_{2}\right)$, triacylglycerol within the muscle itself and fatty acids from adipose tissue could be converted to $\mathrm{CO}_{2}$ in acting muscles, some free amino acids can be released within the muscle itself and from intestinal stores to sustain the amount of ATP generation indispensable for muscle contraction. All single biochemical reactions, but one, need one or several enzymes to activate the conversion of a substrate into a product. The energy transformation in biochemical reactions is led by application of so-called free energy. Reversible and non-reversible reactions within a metabolic pathway are dependent on specific enzymes near or far from equilibrium. Allosteric enzymes are regulatory enzymes that provide the direction in the pathway. $A$ regulatory enzyme is either activated or inhibited by small regulators (ligands). A reversible substrate cycle between $A$ and $B$ is catalyzed by two enzymes with different fluxes. The need of ATP production for muscle contraction is under the leadership of regulatory enzymes and available substrate stores. The improvement of adapted metabolic reactions under sport training depends on the appropriate increase of regulatory enzymes within the glycolytic and oxidative pathways. The amount of some specific enzymes is increased by training in order to improve the maximum activity of the metabolic pathway. Unfortunately, several publications do not precisely implicate the appropriate enzyme(s) to explain or reject the adaptation induced by the training schedule. A few examples will illustrate the factual interpretation and the inadequate allegation.
\end{abstract}

KEY WORDS: Training; Enzymes; Non-equilibrium reactions; Regulatory pathways.

\section{Introduction}

While looking to the scientific literature reported in most periodicals, the facts and interpretation of energy utilization during single exercises and training schedules are based on general information obtained by textbooks on general biochemistry. All biochemical pathways or processes are based on the utilisation of one single molecule, ATP (Adenosine Tri-Phosphate), from bacteria to humans. ATP is a nucleotide in which the base adenine is linked to a sugar ribose, itself connected to three inorganic phosphate (Pi). ATP is the only compound that, directly or indirectly, when hydrolysed, transfers chemical energy to all other processes that requires energy, such as muscle contraction.

The development of biochemical tools (such as tissue biopsies and gene access), including molecular biology, has given access to the understanding of basic facts related to single muscle performance and adaptations during training schedules. However, knowing thermodynamic principles do not necessarily provide information about the rate at which a reaction will proceed ${ }^{1}$. Enzymology is central to biochemistry but one has to know the limit of thermodynamic and kinetic principles of numerous enzymes and more precisely factors that change the activity of an enzyme. Moreover, the use of recent molecular biology techniques, such as the use of mRNA determination of an enzyme molecule, does not necessarily predict its synthesis. Additionally, some enzymes are "regulatory enzymes" that activate or inhibit the activity of a metabolic pathway, and thus the maximal activity obtained from that pathway. Unfortunately, some publications, even with high level of impact factors, 
do not take care of the limitations imposed by enzyme kinetics. Let us remember specific words written down by a famous exercise biochemist, Eric A. NEWSHOLME, as well a marathon runner:

Despite the strength of the theory underlying this approach (maximum flux rate of enzymes) and the direct experimental evidence in support of it, many studies have and still attempt to provide quantitative information about fluxes from activities of 'near-equilibrium' enzymes, such as lactate dehydrogenase for glycolysis, citrate synthase for the Krebs cycle and hydroxyacylCoA dehydrogenase for the fatty acid oxidation. This is particularly depressing considering that experiments on humans involve invasive techniques and can be extremely expensive ${ }^{2}$.

The major aims of the present review is to try to shed light on appropriate interpretation of results obtained on human subjects involved in exercise training, to separate the wheat from the chaff.

\section{General metabolic pathways during exercise}

To perform muscle fibre contraction, there is a need for energy released from one single molecule, ATP converted to ADP (adenosine diphosphate) and Pi (inorganic phosphate). However, the total quantity of ATP molecules in human skeletal muscle is very low (5-6 mmoles $/ \mathrm{kg}$ ) and the energy demand for muscle contraction would be sufficient to sustain intensive shortening for only 2-3 seconds. Thus, a variety of fuels that lead to generation of ATP from ADP and Pi are needed to replenish this local tiny store. Besides ATP store, the striated muscle has also an almost immediate energy supplier called phosphorylcreatine (PC: 15-20 mmoles $/ \mathrm{kg}$ ) which transfers its phosphate group to ADP, replenishing therefore the ATP molecule during or after muscle contraction. However, this PC store would maintain theoretically heavy muscle contraction for another few seconds $(<7 \mathrm{~s})$ : not enough to beat the actual World $100 \mathrm{~m}$ dash! It appears therefore that other energy fuels are needed to sustain muscle activities during sport events.
Catabolic reactions from food supplies and body reserves (muscles, liver, adipose tissues). Original macromolecules are hydrolyzed to single constituents giving rise to acety| and a few molecules of ATP and protons $\left(\mathrm{H}^{+}\right.$and NADH) in the cytosol. Mitochondria (mainly) contributes heavily to the release of 2-3 carbon molecules from the three food substances to enter the Citric Acid Cycle (Hans A "Krebs Cycle") to produce more reduced cofactors (NADH and FADH ${ }_{2}$ ) and $\mathrm{H}^{+}$. On the inner surface of the inner mitochondria the protons enter into the sequence of electron transfer complexes in the chain of oxidative phosphorylation where most ATP synthesis will be produced from ADP and Pi molecules. The remaining body waste products are expelled by respiration $\left(\mathrm{CO}_{2}\right)$ and urine $\left(\mathrm{NH}_{3}\right.$, urea) to satisfy other living organisms.

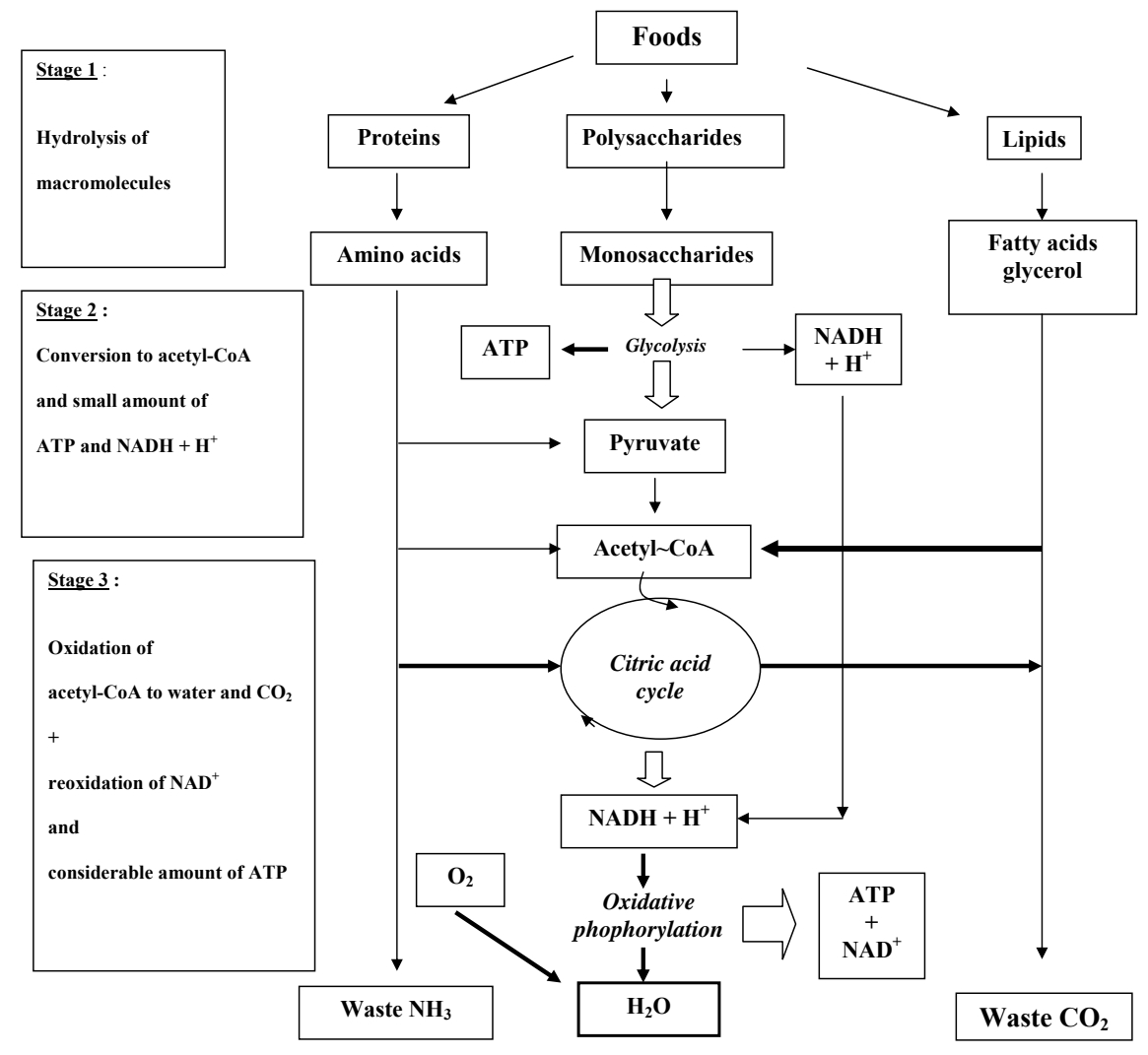

FIGURE 1 - Illustrates the origin of ATP generation from food feeding and local human reserves (muscles, liver, adipose tissue). 


\section{Stage 1}

Polymer molecules (proteins, carbohydrates, lipids) are converted to elementary substrates (amino acids, monosaccharides, fatty acids and glycerol). Those hydrolysed reactions do not liberate energy immediately used by the muscle cells.

\section{Stage 2}

The monomere substrates are converted to simple molecules of three (pyruvate) or two (acetate) carbon, giving a few supplies of free energy molecules as ATP as well as reduced molecules (NADH, Nicotinamide Adenine Dinucleotide reduced-H).

\section{Stage 3}

All previous small molecules are converted to acetyl-CoA (acetyl-coenzyme A), then to a variety of metabolic pathways (such as the citric acid cycle, the ß-oxidation reaction) which release reduced molecules, $\mathrm{NADH}, \mathrm{FADH}_{2}$ (Flavine Adenine Dinucleotide reduced $-\mathrm{H})$. The latter two molecules react with free oxygen $\left(\mathrm{O}_{2}\right)$ in the mitochondria giving enough energy to recombine ADP and Pi to ATP molecules.

In human skeletal muscle (such as the vastus lateralis of the quadriceps), the ATP and PC levels are low, as compared to the local stores of macromolecules $^{1,3}$ (TABLE 1).

Moreover, in the whole organism, the available stores of energetic substances are diversely distributed. It appears that glycogen molecules are mainly located in skeletal muscles and liver, while triglycerides are stored in adipose tissues (visceral organs mainly) (TABLE 2).

Additionally one has take into account the maximal energy released from each type of substrates (TABLE 3).

It appears that the maximal power released from muscle contraction comes from the few ATP itself which is very rapidly restored the other reserve stores. The energy release from ATP hydrolysis is thus obtained from direct small reserves of ATP and PC stores within the muscle fibres, then using the glycolytic pathway down to pyruvate ending by the oxidation pathways. Newsholme et al. ${ }^{4}$ estimated that the energy release from the glycolytic pathway (also called anaerobic glycolysis) amounts to $97-98 \%$ for a $100 \mathrm{~m}$-dash, nearly $50 \%$ during a $800 \mathrm{~m}$-run, and about 3\% for a 5,000 m distance run. HOCHACHKA and SOMERO 5 gave a schematic estimation of metabolic rate (expressed as \% of maximum) from the different substrates towards the intensity of the exercise (FIGURE 2).

Eventually, the estimation of the metabolic fluxes releasing energy within a skeletal muscle fibre depends in fact upon two main factors: 1) the availability of the energy stores (muscle and periphery); 2) the maximal activity of the specific enzymes.

Besides the compulsory need of metabolic compounds, the catalysis of the various energy substances is absolutely connected to specific organic molecules acting at physiological temperature: enzymes.

TABLE 1 - Distribution of energy stores in the human vastus lateralis ${ }^{3}$.

\begin{tabular}{lccc}
\hline Substrates & $\begin{array}{c}\text { Fresh tissue } \\
\left(\boldsymbol{\mu} \mathbf{m o l . g} \mathbf{g}^{-1}\right)\end{array}$ & $\begin{array}{c}\text { Energy content } \\
\left(\mathbf{k J . m o l} \mathbf{~}^{\mathbf{1}}\right)\end{array}$ & $\begin{array}{c}\text { Disposable energy } \\
\left(\boldsymbol{\mu m o l ~} \sim \mathbf{P . g}^{-1}\right)\end{array}$ \\
\hline ATP & 6 & 44 & $5.1(1)$ \\
PC & 15 & 58 & $9.9(2)$ \\
Glycogen (glucose residue) & 121 & 2,900 & 4,350 \\
Triglycerides (ex.palmitate) & 9 & 29,300 & 3,510 \\
Amino acids (free) & 36 & 1,870 & 800 \\
\hline
\end{tabular}

(1) $=90 \%$ ATP, $10 \%$ ADP and AMP; (2) $=67 \% \mathrm{PC}, 33 \%$ creatine. 
TABLE 2 - Total energy stores in male human subject (70 kg body weight, $28 \mathrm{~kg}$ muscle mass, 15\% fat mass), in the prandial phase ${ }^{3}$.

\begin{tabular}{lcc}
\hline Substrates & $\begin{array}{c}\text { Total dry weight } \\
(\mathbf{k g})\end{array}$ & $\begin{array}{c}\text { Disposable energy } \\
(\mathbf{k J})\end{array}$ \\
\hline Triglycerides & 10.5 & 338,500 \\
Proteins & 6 & 78,250 \\
Glycogen & & \\
$\quad$ Liver & 0.100 & 1,700 \\
$\quad$ Muscles & 0.500 & 8,500 \\
Blood (glucose, fatty acids) & 0.023 & 420 \\
PC & 0.087 & 17 \\
ATP & 0.076 & 5 \\
\hline
\end{tabular}

TABLE 3 - Estimation of power released from the different energy stores within a human muscle ${ }^{6}$.

\begin{tabular}{lcc}
\hline Substrates & Final products & $\begin{array}{c}\text { Maximal power output } \\
-\mathbf{P}\left(\boldsymbol{\mu} \mathbf{m o l} \cdot \mathbf{g}^{-\mathbf{1}} \mathbf{s}^{\mathbf{1}}\right)\end{array}$ \\
\hline ATP & $\mathrm{ADP}$ & 3.00 \\
PC & Creatine & 1.60 \\
Glycogen & pyruvate, lactate & 1.00 \\
Glycogen & $\mathrm{CO}_{2}, \mathrm{H}_{2} \mathrm{O}$ & 0.50 \\
Free fatty acids & $\mathrm{CO}_{2}, \mathrm{H}_{2} \mathrm{O}$ & 0.24 \\
Amino acids & $\mathrm{CO}_{2}, \mathrm{H}_{2} \mathrm{O}$ & $?$ \\
\hline
\end{tabular}

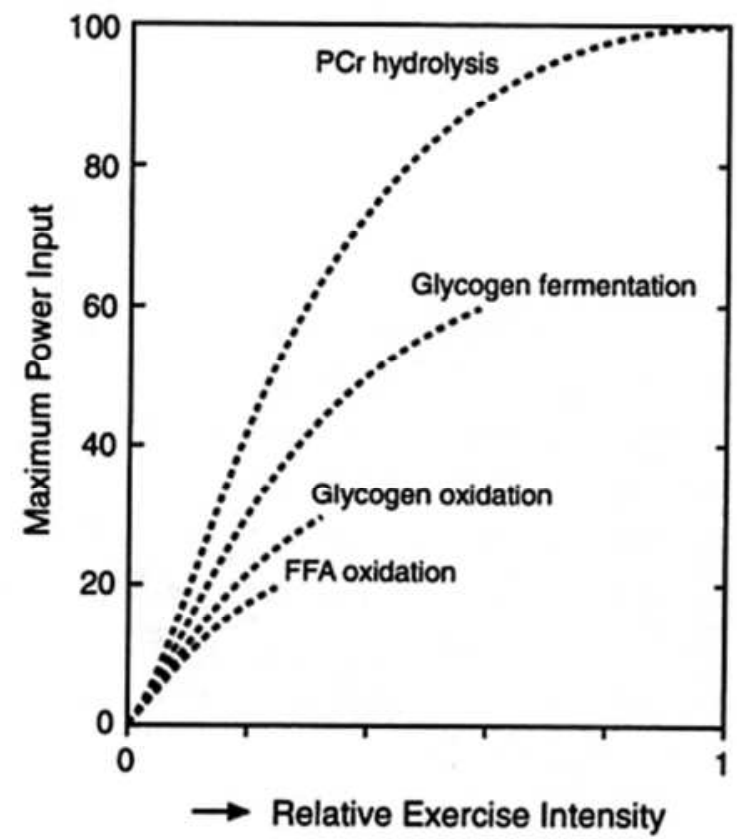

FIGURE 2 - Relationship between fuels, major pathways, and maximum metabolic rate during exercise of progressive intensity 5 . 


\section{Regulation of enzyme activities}

All reactions, but one (creatine to creatinine), in the human body are under enzyme activities that proceed at a satisfactory rate in the cell. Enzymes are protein molecules (one or several molecules) having a catalytic action inside their structure. This active side is a three-dimensional structure that binds the substrate to the enzyme complex, which results in catalysis. The enzyme-substrate complex, which involves weak bonds, is readily reversed. The enzyme-substrate complex formation occurs if the substrate has groups of atoms that are in the correct three-dimensional orientation to interact with the binding atoms in the active site. Concentrations of substrates, temperature, protons ( $\mathrm{pH}$ of the milieu) change the catalytic activity of an enzyme.

The catalytic activity of an enzyme is measured by the rate of its reaction proportional to the concentration of the enzyme. It varies according to the substrate concentration through a hyperbolic curve from first order (the activity increases approximately linearly with the increase in substrate concentration) to zero order (the substrate concentration has very little effect on the rate of reaction (see FIGURE 3a). However, the activity of some enzymes shows a sigmoid curve indicating that the activity of that enzyme can be either reduced or activated by small molecules (ligands) at the same concentration of the substrate (see FIGURE 3b). The latter type of enzyme belongs to an "allosteric" model of a better physiological significance. Indeed, the allosteric enzymes belong to the "substrate cycle system" of reversible reactions where the $A$ to $B$ reaction led by one enzyme is reversed by reaction $B$ to $A$ by another enzyme. The maximal catalytic activity (Vmax) of an enzyme and its half $\mathrm{Vmax}$ (maximal velocity), expressed by the Michaelis-Menten constant (Km), has a physiological significance which can estimate the metabolic flux of a series of reactions.

(a)

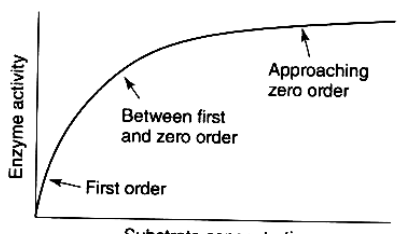

(b)

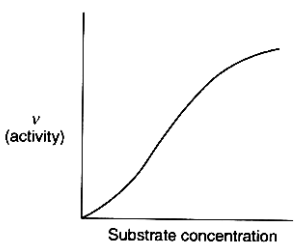

(a) First and zero order components of hyperbolic curve of enzyme activity against substrate concentration; (b) Sigmoid response of enzyme activity against substrate increase showing a greater inhibitory effect at lower concentration. The numbers represent the effect on the maximum activity of the enzyme, as compared to FIGURE (3a);

(c) Percentage of maximum activity of hexokinase and glucokinase against glucose concentration released specifically to muscle and liver. The difference of curves emphasizes a faster saturation of the enzyme in muscle tissue as compared to hepatocytes.

FIGURE 3 - General enzyme activities (Adapted from Newsholme and LeEch'1).

The Km value also provides information about the role of similar regulatory enzyme systems in different cells, such as the first step of glucose reaction in the glycolytic pathway (glucose to glucose-6-phosphate, G6P) (FIGURE 3c). In skeletal muscle, the hexokinase action has a very-low $\mathrm{Km}$, meaning the enzyme is rapidly saturated by its substrate; in liver, the first step by glucokinase is never saturated by higher physiological concentration. Thus, FIGURE 3c demonstrates that muscle glucose uptake is rapidly 
saturated by normal concentration of arterial glucose, while liver can rapidly phosphorylate this sugar to be converted to glycogen stores after a meal (for example).

Another value has a fundamental importance in understanding the relationship between biochemical pathways: the Gibbs free energy concept which combines the first and second laws of thermodynamics. Gibbs, an American scientist, used the definition of enthalpy (the heat produced by a reaction) together with the entropy (molecular disorder induced by the reaction) to determine the direction of a reaction of biochemical pathway:

\section{$\mathrm{A} \longleftrightarrow \mathrm{B}$}

$\Delta \mathrm{G}^{\mathrm{o}}=-2.3 \mathrm{RT} \log \mathrm{Keq}$ (1 mole concentration of $B$ and $A$ )

$\Delta \mathrm{G}=\Delta \mathrm{G}^{\mathrm{o}}+2.3 \mathrm{RT} \log \Gamma(\Gamma=$ real concentration of $B$ and $A$ )

$$
\Delta \mathrm{G}=-2.3 \mathrm{RT} \log \mathrm{Keq} / \Gamma
$$

Practically, the previous enzymatic properties means that one has to take into account the $\mathrm{Km}$ of each enzyme involved in the regulatory flux of the pathways, together with the inhibitor and stimulating actors of a precise substrate cycle. This approach is compulsory to understand the several hundred-fold increase of the glycolytic flux as soon as one is facing high intensive exercise.

Besides the free energy concept, one has also to consider the coupling of biochemical reactions. A twosubstance reaction $\mathrm{A} \rightarrow \mathrm{B}$ can be coupled-in-parallel with another reaction $\mathrm{X} \rightarrow \mathrm{Y}$ by one specific enzyme $\mathrm{E} 1$. However, in many cases, the $\mathrm{X}$ molecule is regenerated through another couple $\mathrm{C} \rightarrow \mathrm{D}$ by another specific enzyme E2. Under those conditions we need to know the precise metabolic flux (in Joules or kcal) of these irreversible reactions (to evaluate the predominance of the real flux between the two reactions J1 and J2).

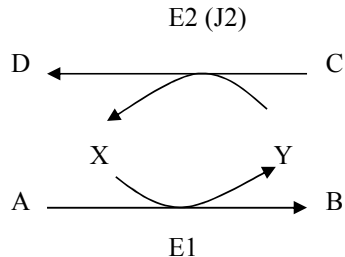

One example may clarify this concept: the substrate cycle between fructose-6-phosphate (F6P) and fructose-1,6-bisphosphate (F-1,6-BP) in muscle glycolysis under resting condition. The numbers express the metabolic flux $\mathrm{J}\left(\mu \mathrm{mol}^{-1} \mathrm{~kg} \cdot \mathrm{min}^{-1}\right)$ in the human vastus lateralis ${ }^{1}$.

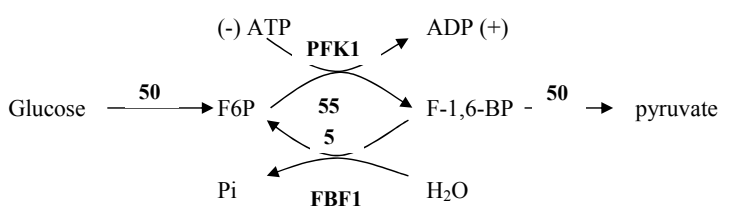

The enzyme phosphofructokinase 1 (PFK1) is inhibited by a resting level in ATP, while it will be activated by an excess of ADP released under heavy exercise. It may be already visualized that the synthesis to glucose from pyruvate is a much slower process. This observation points out another important fact related to kinetic reaction within a substrate cycle. We may consider the existence of equilibrium and nonequilibrium reactions within a substrate cycle. When there is a maximum catalytic activity for one enzyme as compared to a much lower activity for the other enzyme, this situation characterises a non-equilibrium process. Conversely, a reaction is near-equilibrium if the activities of the two enzymes are close to each other. Thus in the above example of PFK1, we are facing a far-from equilibrium reaction, the enzyme activity being moderate with a high ATP/ADP ratio (resting condition), or at full maximal activity under a low ATP/ADP ratio (exercise condition).

\section{Metabolic regulation of carbohydrates}

Glycogenolysis and glycolysis within skeletal muscle fibres are regulated by far-from equilibrium enzymes. Glucose taken up by blood supply (from liver glycogen) is catabolized by 10 enzyme reactions down to pyruvate. Only three substrate cycles induced by far-from equilibrium enzyme systems are involved in the regulation of the glycolytic flux from glucose to pyruvate (FIGURE 4). Those enzymes are either activated or inhibited by small molecules (ligands) involved in local metabolism, such as ATP, ADP, AMP, Pi, PC. 


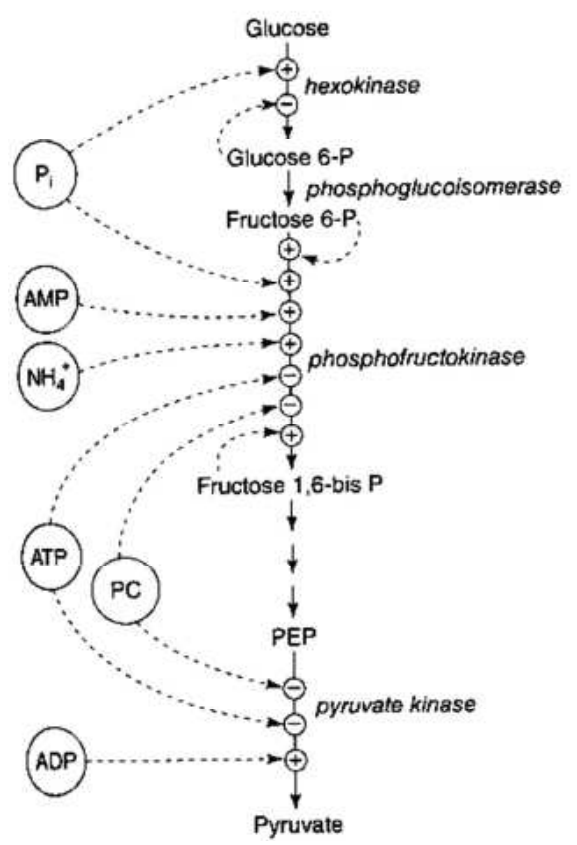

Three regulatory enzymes lead the way glycolysis down to pyruvate. Small molecules will act to stimulate (ADP, AMP, $\mathrm{Pi}, \mathrm{NH}_{4}^{+}{ }^{+} \ldots$ ) or reduce (ATP, $\mathrm{PC}, \ldots$ ) glycolysis according to the need to enhance, or not, the synthesis of new molecules of ATP for muscle contraction, as an example.

FIGURE 4 - Factors involved in regulation of keys steps in glycolysis. Adapted from Newsholme and LEECH ${ }^{1}$.

In order to shed light of these regulatory couples, one has to analyze the free energy status of enzymes involved in striated muscle glycolysis ${ }^{3}$ (TABLE 4).

All three enzymes leading to the production of pyruvate from glucose are far from equilibrium. Moreover, muscle glycogen degradation to glucose molecules is led by another substrate cycle that involves glycogen phosphorylase and glycogen synthase $^{3}$ (FIGURE 5).

Phosphorylation of the two enzymes by ATP and a specific protein kinase has opposite action on glycogen molecule. Doing so during exercise, the release of one glucose molecule is favoured, while glycogen synthesis is inhibited, the two enzymes being next to glycogen molecules.

The entrance of pyruvate into mitochondria is the next step under enzyme regulation. The oxidation and decarboxylation of pyruvate by pyruvate dehydrogenase (PDH) and its NAD cofactor releases acetyl-CoA and $\mathrm{NADH}+\mathrm{H}^{+}$. Indeed, under resting condition, the $\mathrm{PDH}$ action is slow down by the available concentration of ATP. Then, the acetyl-CoA enters the citric acid cycle (CAC, also call the Krebs cycle) were molecules of $\mathrm{NADH}, \mathrm{FADH}_{2}, \mathrm{H}^{+}$are released (as co-enzymes) using specific enzymes (FIGURE 6).

Again, the flux of the CAC is led by three allosteric enzyme systems (out of a total of 8 enzymes), all far from equilibrium. These enzymes are activated or inhibited by their co-factors being in excess, such as ATP, NADH, ADP, $\mathrm{Ca}^{2+}, \ldots$. Citrate synthase (CS), isocitrate dehydrogenase (ICDH) and oxoglutarate dehydrogenase (2-OGDH) are the key enzymes regulating the flux of the $\mathrm{CAC}$ by non-equilibrium reactions. However, the limiting flux of the cycle is under the leadership of the lowest activity member, 2-OGDH. This explain why the oxidative flux of CAC (unit of metabolite.g tissue $\mathrm{e}^{-1} \cdot \mathrm{min}^{-1}$ ) is much lower than that obtained by glycolysis.

From those experimental observations, one has to choose the correct enzyme system to understand why there is no anarchy within a resting muscle. When there is no need to produce new ATP molecules in the oxidative phosphorylation system (such at rest), the regulatory enzymes slow down the activation of the glycolytic and mitochondrial pathways, favouring the synthesis of carbohydrates (and fat molecules, indirectly). How to become overweight while overeating and keeping out of exercise...!

TABLE 4 - Standard free and real energy released in skeletal human muscle.

\begin{tabular}{lcccccc}
\hline Enzymes & $\begin{array}{c}\Delta \mathbf{G}^{\mathbf{0}} \\
\mathbf{k J . m o l}^{\mathbf{1}}\end{array}$ & $\mathbf{K e q}$ & $\Gamma$ & $\mathbf{K e q} / \Gamma$ & $\begin{array}{c}\boldsymbol{\Delta G} \\
\mathbf{k J . m o l}^{\mathbf{1}}\end{array}$ & Equilibrium \\
\hline Hexokinase & -20.9 & 4,700 & 0.08 & 59,000 & -27.9 & far from \\
Phosphofructokinase & -17.1 & 1050 & 0.03 & 35,000 & -26.5 & far from \\
Aldolase & +23.0 & $1.10^{-4}$ & $9.10^{-5}$ & 11 & -6.1 & near \\
Pyruvate kinase & -24.7 & 2,000 & 40 & 500 & -15.8 & far from \\
\hline
\end{tabular}


When there is a need of excess energy, such as during exercise, glycogen release molecules release glucose to enter glycolysis. Proteins kinases stimulate the phosphorylation of glycogen phosphorylase a (GP-a), which become active, while inhibiting glycogen synthase b (GS-

b). Thus, the release of glucose molecules is stimulated to enhance the production of ATP molecules in sarcoplasmic and mitochondrial sites. After exercise, the reverse situation occurs to refill the glycogen store. Again, the concentration of small molecules (ATP, ADP), together with specific hormone stimuli (adrenaline, ...), appear to lead the compulsory need to replenish the less content of energy stores: ATP.

Phosphorylation of PDH inhibits the enzyme (PDHb) whereas phosphorylation activates the enzyme (PDHa). Increase in $\mathrm{Ca}^{2+}, \mathrm{ADP}, \mathrm{NADH}$ concentrations are thus the main stimuli to foster the activity of the Citric Acid Cycle, and thereafter the production of new ATP molecules.

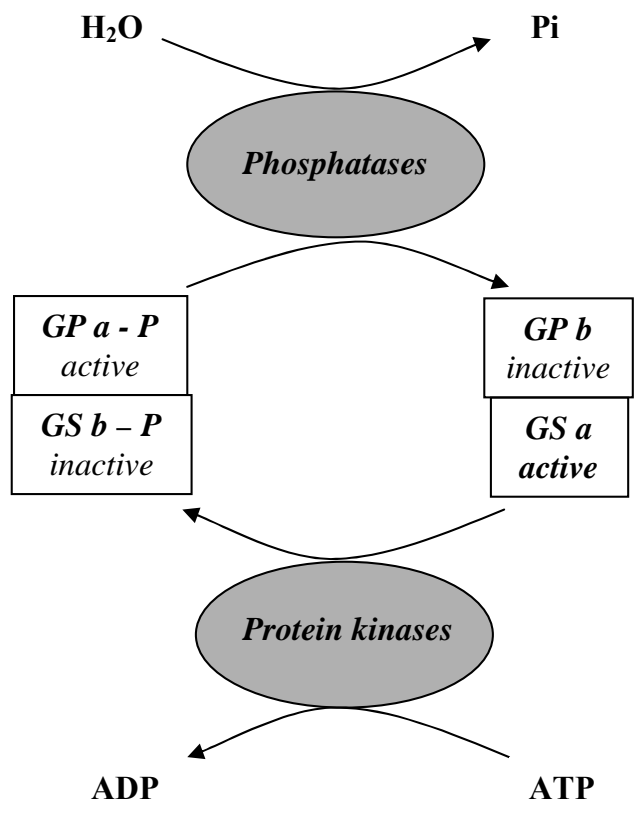

FIGURE 5 - Mechanism of adaptation of glycogen degradation or synthesis in muscle and liver tissue according to the demand of energy. All enzymes are closed to the glycogen granules located in the cytosol.

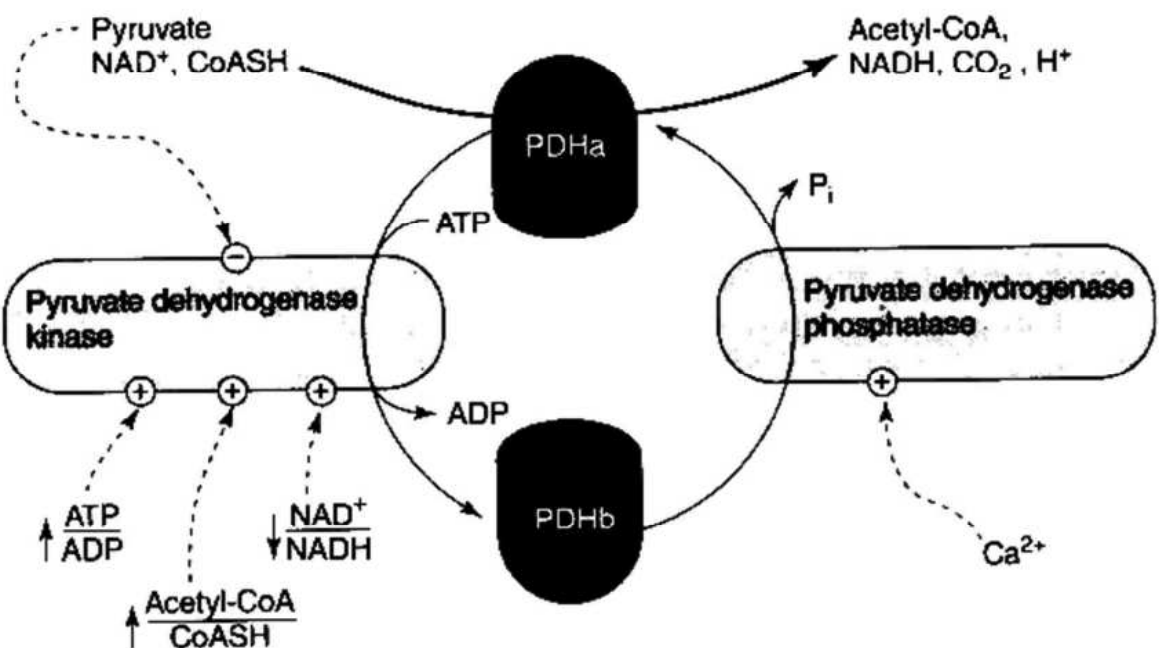

FIGURE 6 - Regulation of the activity of pyruvate dehydrogenase (PDH) by small molecules from metabolic cycles (Adapted from Newsholme and LeECH'). 


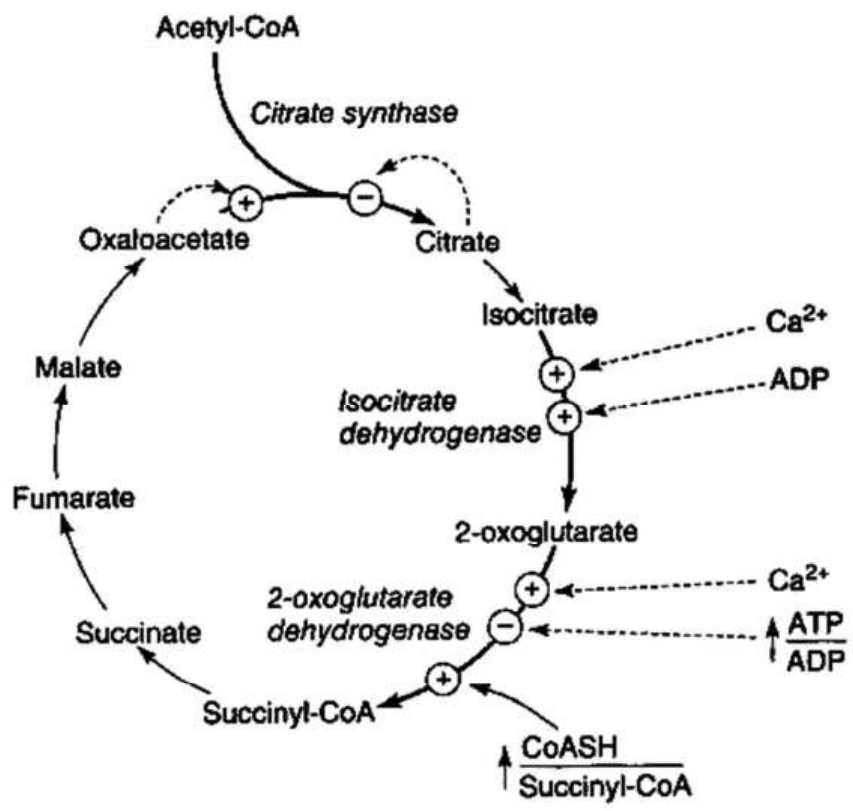

Intense exercise enhances the amount of $\mathrm{Ca}^{2+}$ within the mitochondria amplifying the activity of ICDH and 2-OGDH, together with the increase of ADP content.

FIGURE 7 - Control of the metabolic flux of the CAC during physical exercise (Adapted from NEwSHOLME and LEECH').

\section{Metabolic regulation of fatty acids}

The next regulation to investigate, as far as the limitation factor is concerned, is the transfer of free fatty acids into the mitochondria. The fatty acid has to be linked to coenzyme $\mathrm{A}(\mathrm{CoA})$ in the cytoplasm, forming a fatty acid-CoA molecule which is transported across the external membrane of the mitochondria to react with carnitine (an amino acid derivative synthesized in the liver and the kidney) by a specific enzyme, the fatty acid-carnitine. Taking an example with a $\mathrm{C} 16$ fatty acid molecule (palmitate), the enzyme is called carnitine palmitoyltransferase 1 (CPT1) (FIGURE 8).
A translocase transfers the fatty acid-carnitine complex through the inner membrane of mitochondria and another fatty acid-carnitine complex (herewith CPT2) liberates the fatty acid to the matrix of the mitochondria where each fatty acid will enter the so-called ß-oxidation pathway (each long-chain fatty acid is oxidized step by step releasing acetyl-CoA molecules which enter into the Krebs cycle).

The limitation step of fatty acid oxidation is the carnitine acyltransferase complex having a low $\mathrm{Km}$, and thus a rapid saturated flux.

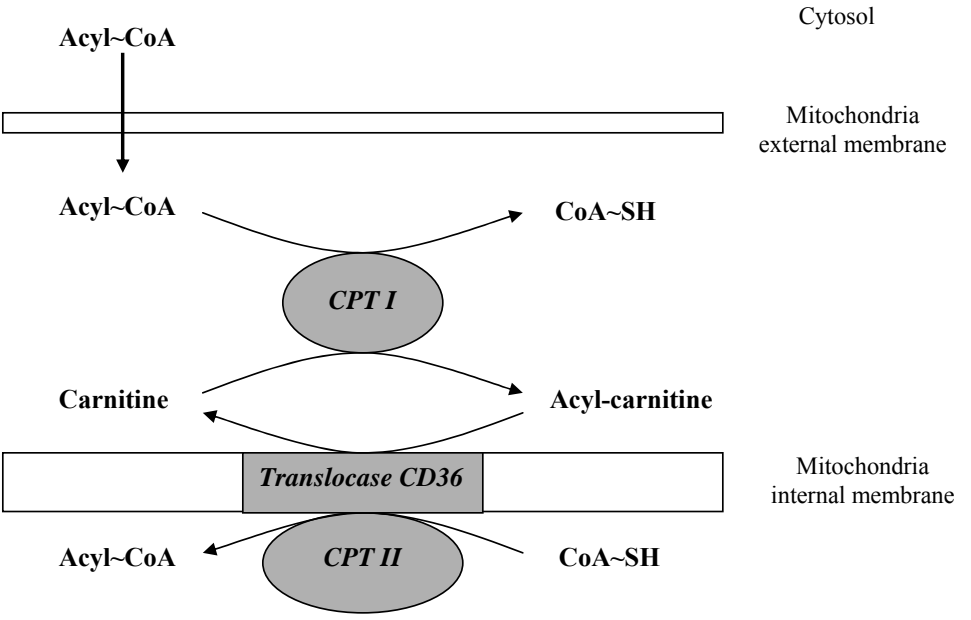

Carnitine palmitoyl transferases (CPTI and II) are located on the outer (CPTI) and inner (CPTII) surface of the inner side of the inner membrane of the mitochondria. They are reacting with all longchain fatty acid. The incorporation of free fatty acids to the matrix of mitochondria and their access to the CAC are thus limited by the maximal activity of the CPTI and II.

FIGURE 8 - Transport of long-chain fatty acid molecules across the inner mitochondrial membrane. 


\section{Metabolic adaptations during exercise in human subjects}

The effect of different types of running on contents of glycogen (muscle and liver) and muscle concentrations of ATP, ADP, PC, Pi and lactate have been measured to evaluate, indirectly, the stimulation of specific metabolic pathways ${ }^{1}$ (TABLE 5):

TABLE 5 - Effect of running exercise on muscle glycolysis in human subjects ${ }^{1}$.

Concentrations are expressed as $\mu \mathrm{mol} \cdot \mathrm{g}^{-1}$ wet weight $\left(\mu \mathrm{M} \cdot \mathrm{g}^{-1}\right)$.

\begin{tabular}{|c|c|c|c|c|c|c|}
\hline Activities & $\begin{array}{c}\text { Glycogen } \\
\text { (\% from rest) }\end{array}$ & $\begin{array}{c}\text { ATP } \\
\mu \mathrm{M} \cdot \mathrm{g}^{-1}\end{array}$ & $\begin{array}{c}\text { PC } \\
\mu \mathrm{M} \cdot \mathrm{g}^{-1}\end{array}$ & $\begin{array}{c}\mathbf{P i} \\
\mu \mathrm{M} \cdot \mathrm{g}^{-1}\end{array}$ & $\begin{array}{l}\text { Lactate } \\
\mu \mathrm{M} \cdot \mathrm{g}^{-1}\end{array}$ & $\begin{array}{c}\text { ATP/ADP } \\
\text { ratio }\end{array}$ \\
\hline Rest & 100 & 6.2 & 22.0 & 1.0 & 0.75 & 60 \\
\hline $400 \mathrm{~m}$ & 85 & 5.2 & 1.9 & 27.0 & 23.00 & 5 \\
\hline $2 \mathrm{~km}$ & 81 & 5.0 & 4.2 & 22.0 & 28.00 & 5 \\
\hline $21 \mathrm{~km}$ & 11 & 5.7 & 7.2 & 25.0 & 3.50 & 5 \\
\hline
\end{tabular}

It appears that short sprinting lowers PC concentration but has a reduced effect on glycogen stores. On the contrary, long distance endurance running depleted mostly glycogen content but has a moderate depletion in PC store and lactate production. In all exercise conditions, the muscle ATP store remains relatively high, but the Pi shows a major increase while the estimated ATP/ADP ratio drops to $10 \%$ as compared to resting condition. Thus, it seems quite clear that small ligands, such as $\mathrm{Pi}, \mathrm{ADP}$ leads to the activation of specific regulatory enzymes.

How could we investigate the metabolic adaptation related to any modification of a specific pathway (being activated, or not), as evidence of a change in enzyme activity ? The answers are: 1) to choose the right limiting enzyme in a metabolic cycle; 2 ) to measure the quantity of that enzyme. The latter investigation implies the isolation of that enzyme knowing that the metabolic flux is directly related to the amount of enzyme available in that tissue. At first glance, as soon as we do identify the limiting enzyme, we have to apply the general mechanism of protein synthesis through the usual sequence: DNA $\rightarrow$ mRNA $\rightarrow$ protein synthesis. For many years, molecular biologists did apply this sequence using highly specific tools. Nevertheless, we now know that mRNA amplifications do not implicitly postulate that new molecules of enzymes (proteins) have been made up in a tissue. Moreover, the last decade gave us new tools to investigate biogenesis in skeletal muscle: the discovery of microRNA (miRNA) that posttranscriptionally regulates the expression of target genes ${ }^{8}$. The miRNAs are a class of about 22 nucleotide in all animals, plants and unicellular eukaryotes non-coding RNAs that control diverse biological functions ${ }^{9}$. DNA proportion from miRNA molecules represent about $60 \%$ of the total DNA package within a cell, while DNA leading to protein synthesis is near to $2 \%$ of the whole DNA particules ${ }^{10}$. Over 1000 miRNAs have been identified within the human genome, and a single miRNA may inhibit several target genes, thus acting on skeletal muscle differentiation, such as during skeletal myogenesis $^{11-12}$. The increased production of miRNA will slow down the synthesis of new protein molecules by inducing mRNA cleavage, either by translational inhibition and or by promoting the degradation of target mRNA, thus inhibiting the production of new protein molecules.

For certain, miRNAs are playing a major role in explaining adaptations to cardiac ${ }^{13-14}$ and skeletal muscle hypertrophy in resistance exercise training? in sarcopenia ${ }^{15}$. Apparently, results from plasma circulating miRNAs might have potential value as physiological mediators of exercise-induced cardiovascular adaptation in athletes ${ }^{16}$.

Looking to the effects of exercise training, it becomes clear one needs to choose the correct enzymes to evaluate changes of specific metabolic adaptations in skeletal and cardiac muscles. 


\section{Factual interpretations and inadequate allegations}

Numerous publications, even in high standing periodicals, concluded on the consequence of exercise training by inadequate interpretations of correct experimental data using either nonequilibrium enzymes or miRNA modifications without consecutive quantitative and appropriate enzyme results.

As noted by Newsholme and Leech ${ }^{1}$ several authors concluded on adaptations induced by exercise training using lactate dehydrogenase (LDH), citrate synthase (CS), succinate dehydrogenase (SDH) (publications), ... or more recently from mRNA increases of CS and PGC1 $\alpha$ (Peroxisome proliferators-activated receptot- $\Upsilon$ coactivator) without an enhanced production of the appropriate enzyme protein ${ }^{17}$.

Other publications use statistical conclusions to postulate a relationship adaptation induced by nutritional supplementation $^{18-19}$, low-intensity exercise ${ }^{20}$. In those latter publications, the authors used correct statistical methods but emphasized their conclusions using $\mathrm{r}$ or $\mathrm{r}^{2}$ values showing that 50 to $80 \%$ of their populations do not satisfy the relationship between the two variables.

The most stimulating conclusion on exercise adaptations seems to be the comparison between two different animal species: man versus other vertebrates. TABLE 6 gives us some examples on moving capacities between two species.

TABLE 6 - Comparison of performance between endurance athletes, man and humming bird ${ }^{3,21}$.

\begin{tabular}{|c|c|c|}
\hline Regulatory enzymes & $\begin{array}{l}\text { Humming bird } \\
\left(\mu \mathrm{mol} \cdot \mathrm{g}^{-1} \cdot \mathrm{min}^{-1}\right)\end{array}$ & $\begin{array}{c}\text { Man } \\
\left(\mu \mathrm{mol} \cdot \mathrm{g}^{-1} \cdot \mathrm{min}^{-1}\right)\end{array}$ \\
\hline Hexokinase & 18.4 & 3.4 \\
\hline Glycogen phosphorylase & 32.2 & 14.0 \\
\hline Phosphofructokinase & 108.8 & 66.0 \\
\hline Carnitine palmitoyltransferase & 7.2 & 1.9 \\
\hline$\alpha$-oxoglutarate dehydrogenase & 9.6 & 3.0 \\
\hline
\end{tabular}

Comparing the activities of some regulatory enzymes of the carbohydrates and fatty acids substrate of a man and a humming bird, we have to admit the metabolic efficiency of the flying animal is more adapted to release energy for its exercise activities. The maximal activities of specific enzymes leading to ATP production in the cytosol and mitochondria are from 2 to 3.5 fold higher in pectoral muscle of the humming bird as compared to the vastus lateralis of a human endurance runner ${ }^{3,21}$.
Eventually, we are still in the indecision state while looking to the precise role of miRNA adaptations induced, or not, by exercise training. Presently, we are aware of the importance of miRNA influence upon adaptations induced by exercise training. For example GÜLLER and RUSSELL ${ }^{22}$ observed a specific reduction of miRNA molecules while examining the consequences of resistance and endurance training sessions (FIGURE 9). 
Several authors postulated the effect of decreased production of different miRNAs upon the activation of protein synthesis specifically involved in exercise adaptation. However, the initial signals that inhibit the production of miRNA are still under intense investigation.

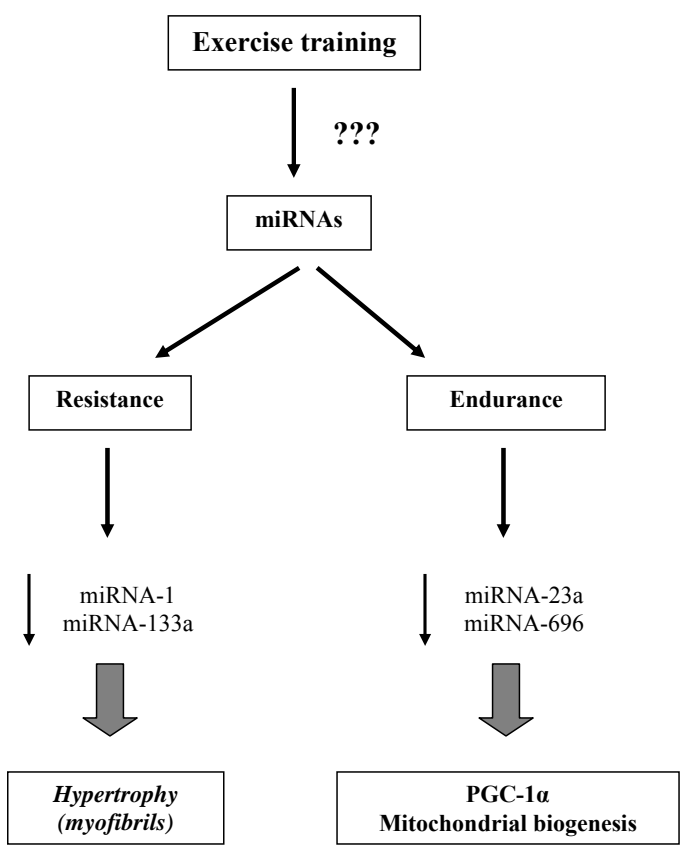

FIGURE 9 - Influence of micro-RNAs (miRNA) on the production of new protein molecules (enzymes, structural proteins) in skeletal muscles. Adapted from GüLLER and RuSSELL ${ }^{22}$.

Moreover, a recent publication emphasizes the action of miRNA-34a upon cardiac ageing and function in humans ${ }^{23}$. The quantity of miRNA-34a is regularly enhanced from childhood to elderly. However, we still need to know details on the precise actions induced through miRNA modifications: what are the signals acting upon some small DNA fragments of miRNA synthesis? Synthesis of miRNAs is reduced to enhance new protein molecules (such as during exercise training), while they are increased to slow down the synthesis of enzymes and structure proteins under specific conditions (such as ageing).

These recent years, besides mRNAs and miRNAs, it has been discovered that single RNAs could form circular RNA molecules (circRNAs) that are predominant transcript isoforms in hundreds of human genes ${ }^{24}$. In March 2013, a paper of MEMCZAK et al. published in "Nature" provides evidence that numerous circRNAs (about 100 nucleotides each) form an important class of post-transcriptional regulators in human tissues ${ }^{25}$. Their data argue that circRNAs can be used as potent inhibitors of miRNAs, thus inducing protein synthesis in specific tissues. For certain it remains to determine if those recent facts could be applied under physical exercise training. But, once again, what are the signals induced by exercise that stimulate the circRNAs?

In order to evaluate the precise biochemical mechanisms involved in exercise conditions, as well as during training practise, it appears compulsory to focus the attention to the regulatory enzymes in the appropriate metabolic pathway. Enzymes nearequilibrium may be stimulated by general nuclear factors (such as several hormones) but they will not modify the flux of substrates within a specific pathway. On the contrary, the increase of far-fromequilibrium enzymes are needed to evaluate the real fluxes and adaptations observed as a consequence of metabolic increase, especially in substrate transport, the Krebs cycle, and oxidative phosphorylation.

Those regulations seem to be under the expression of circRNAs and mi-RNAs which either increase or reduce protein molecule synthesis. We still need to identify the factors acting on circRNAs and miRNAs synthesis under exercise condition and training adaptation. 


\section{References}

1. Newsholme EA, Leech TR. Functional biochemistry in health and disease. Chichester: Wiley-Blackwell; 2009.

2. Poortmans JR. Principles of exercise biochemistry. In: Borms J, Hills AP, editors. Basel: Karger; 2004.

3. Poortmans JR. Biochimie des activités physiques et sportives. Brussels: De Boeck; 2012.

4. Newsholme EA, Leech T, Duester G. Keep on running. Chichester: Wiley \& Sons; 1994.

5. Hochachka PW, Somero GN. Biochemical adaptations. Oxford: Oxford University Press; 2002.

6. McGilvery RW. The use of fuels for muscular work. In: Howald H, Poortmans JR, editors. Metabolic adaptation to prolonged physical exercise. Basel: Karger; 1975. p. 12-30.

7. Newsholme EA, Start C. Regulation in metabolism. London: Wiley \& Sons; 1973.

8. Yamamoto H, Morino K, Nishio Y, et al. MicroRNA-494 regulates mitochondrial biogenesis in skeletal muscle through mitochondrial transcription factor A and Forkhead box j3. Am J Physiol Endocrinol Metab. 2012;303:E1419-E27.

9. Davidsen PK, Gallagher IJ, Hartman JW, et al. High responders to resistance exercise training demonstrate differential regulation of skeletal muscle microRNA expression. J Appl Physiol. 2010;110:309-17.

10. Adeli K. Translational control mechanisms in metabolic regulation: critical role of RNA binding proteins, microRNAs, and cytoplasmic RNA granules. Am J Physiol Endocrinol Metab. 2011;301:E1051-E64.

11. Ge Y, Chen J. MicroRNAs in skeletal myogenesis. Cell Cycle. 2011;10:441-8.

12. Goljanek-Whysall K, Sweetman D, Münsterberg AE. microRNAs in skeletal muscle differentiation and disease. Clin Sci. 2012;123:611-25.

13. Fernandes T, Soci UPR, Oliveira EM. Eccentric and concentric cardiac hypertrophy induced by exercise training: microRNAs and molecular determinants. Braz J Med Biol Res. 2011;44:836-47.

14. Oliveira-Carvalho V, Fernandes da Silva MM, Guimaraes GV, Bacal F, Bocchi EA. MicroRNAs: new players in heart failure. Mol Biol Rep. 2013;40:2663-70.

15. Drummond MJ, McCarthy JJ, Fry CS, Esser KA, Rasmussen BB. Aging differentially affects human skeletal muscle microRNA expression at rest and after an anabolic stimulus of resistance exercise and essential amino acids. Am J Physiol Endocrinol Metab. 2008;295:E1333-E40.

16. Baggish AL, Hale A, Weiner RB, et al. Dynamic regulation of circulating microRNA during acute exhaustive exercise and sustaining aerobic exercise training. J Physiol. 2011;589:3983-94.

17. Levett DZ, Radford EJ, Menassa DA, et al. Acclimatization of skeletal muscle mitochondria to high-altitude hypoxia during an ascent od Everest. FASEB J. 2012;1431-41.

18. Ørtenblad N, Nielsen J, Saltin B, Holmberg HC. Role of glycogen availability in sarcoplasmic reticulum $\mathrm{CA}^{2+}$ kinetics in human skeletal muscle. J Physiol. 2011;589:711-25.

19. Baguet A, Bourgeois J, Vanhee L, Achten E, Derave W. Important role of muscle carnitine in rowing performance. J Appl Physiol. 2010;109:1099-110.

20. Takada S, Okita K, Suga T, et al. Low-intensity exercise can increase muscle mass and strength proportionally to enhanced metabolic stress under ischemic conditions. J Appl Physiol. 2012;113:199-205.

21. Hochachka PW, Matheson GO. Regulating ATP turnover rates over a broad dynamic work ranges in skeletal muscles. J Appl Physiol. 1992;73:1697-703.

22. Güller I, Russell AP. MicroRNA in skeletal muscle: their role in regulation on regulation in development, disease and function. J Physiol. 2010;588:4075-87.

23. Boon RA, Iekushi K, Lechner S, et al. MicroRNA-34a regulates cardiac ageing und function. Nature. 2013;495:107-10.

24. Salzman J, Gawad C, Wang PL, Lacayo N, Brown PO. Circular RNAsare the predominent transcript isoform from hundreds of human genes in diverse cell types. PLoS One. 2012;7:e30733.

25. Memczak S, Jens M, Elefsinioti A, et al. Circular RNAs are large class of animal RNAs with regulatory potency. Nature. 2013;495:333-8. 
Poortmans JR \& Carpentier A

Jacques Remy Poortmans

ENDEREÇO

Faculté des Sciences de la Motricité

Université Libre de Bruxelles

Route de Lennik 808

Recebido para publicação: 04/06/2013

Aceito: 19/06/2013

CP 640 - B-1070 - Bruxelles - BELGIUM

e-mail: jrpoortm@ulb.ac.be

506 • Rev Bras Educ Fís Esporte, (São Paulo) 2013 Jul-Set; 27(3):493-506 